\title{
Labeling of Piperine with Iodine-131 as Radiotracer in the Development of Cancer Drugs from Indonesia's Natural Products
}

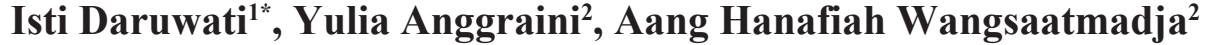 \\ ${ }^{1}$ Center for Applied Nuclear Science and Technology-BATAN, Jl. Taman Sari No.71, \\ Bandung; ${ }^{2}$ Indonesian College of Pharmacy (STFI), Jl. Soekarno Hatta No. 354, Bandung \\ Submitted 4 March 2019; Revised 26 March 2018; Accepted 29 March 2019; Published 13 May 2019 \\ *Corresponding author: isti@batan.go.id
}

\begin{abstract}
Piperine, as one of the secondary metabolites of pepper, shows many pharmacological activities in various studies, including as antiinflammatory, antimicrobial, hepatoprotective, antioxidant, and potentially anticancer agents. Cancer is still one of the leading causes of death in the world due to the absence of specific symptoms in early-stage of cancer. The development of drugs for early diagnosis and selective treatment of cancer cells is considered one of the best solutions to reduce mortality. The activity of piperine that could induce apoptosis of 4T1 breast cancer cells and HT-29 colon cancer cells at in vivo trials prove it as a potential compound that can carry radioactive atoms (as labeledcompound) to cancer cells. This study was conducted to determine the optimal conditions of labeling of piperine with iodine-131 in order to obtain a ${ }^{131}$ I-piperine which can later be used as a radiotracer in the development of cancer drugs. The labeling of piperine was performed by Chloramine-T iodination method and followed by purification with ion exchange chromatography. The optimal labeling results of piperine with $43.99 \% \pm 1.23$ radiochemical purity were obtained with piperine $3 \mathrm{mg} / 300 \mu \mathrm{L}$, chloramine- $\mathrm{T} 50 \mu \mathrm{g}$ as an oxidizer, incubation time $30 \mathrm{~min}$ at room temperature, and $100 \mu \mathrm{g}$ sodium metabisulphite as a reductor. To improve the purity of the preparation, purification by ion exchange chromatography method with Dowex 1X8 mesh 100-200 as resin was used until obtained $93.26 \%$ \pm 0.94 of radiochemical purity. Further research is necessary before ${ }^{131}$ I-piperine can be used as a radiotracer for cancer diagnosis in nuclear medicine.
\end{abstract}

Keywords: cancer, iodine-131, ${ }^{131}$ I-piperine, labeled-compound, radiotracer

\section{Introduction}

Cancer is one of the leading causes of death in the world. The data from the Basic Health Research (Riskesdas) in 2013 from the Ministry of Health of Indonesia showed the prevalence of cancer patients in all ages in Indonesia reached $1.4 \%{ }^{1}{ }^{1}$ This high prevalence of cancer in Indonesia needs to be observed with precautionary measures and early detection. Early detection of cancer is helpful not only to reduce mortality, but also to improve the quality of life of sufferers. ${ }^{2}$ Besides, knowing the staging of a cancer is crucial for determining the most effective treatment(s) and for predicting survival. ${ }^{3}$
Cancer treatment can be done in various ways, including chemotherapy. However, this treatment method still weaknesses, in addition to killing cancer cells, chemotherapy can also affect normal cells that have rapid proliferation rates, such as hair follicles, bone marrow, and digestive tract cells. ${ }^{4}$ Therefore, an alternative is needed for more selective treatment of cancer cells. Radiopharmaceutical is one of these kind of selective treatments.

Radiopharmaceuticals are drugs containing radioisotopes which are safe for administration in humans for diagnosis or therapy. The use of radiopharmaceuticals for imaging organ function and disease states 
is a unique capability of nuclear medicine. The mapping of the radiopharmaceutical distribution in vivo provides images of functional morphology of organs in a noninvasive manner and plays an important role in the diagnosis of many common diseases associated with the malfunctioning of organs in the body as well as in the detection of certain type of cancers. ${ }^{5}$

A radionuclide (radioactive nuclide, radioisotope or radioactive isotope) is an atom that has excess nuclear energy, making it unstable. This excess energy can be used in one of three ways: emitted from the nucleus as gamma $(\gamma)$ radiation; transferred to one of its electrons to release it as a conversion electron; or used to create and emit a new particle (alpha $(\alpha)$ particle or beta $(\beta)$ particle) from the nucleus. ${ }^{6}$ Radiopharmaceuticals used for diagnostic purposes are the ones with $\gamma$-emitting radioactive atoms, whereas radioactive atoms transmitting $\alpha$ or $\beta$ particles are used for internal radiotherapy.

Iodine-131 $\left({ }^{131} \mathrm{I}\right)$ is a $\gamma$-beam and $\beta$-particle-emitting radionuclide. The energy produced from the $\gamma$-beam by ${ }^{131} \mathrm{I}$ is $364 \mathrm{keV}$, while the energy from the $\beta$ particle beam is $0.61 \mathrm{MeV} .^{7}$ For emitting $\gamma$-beam and the $\beta$-particle, and having 8.1 days of half life, ${ }^{131} \mathrm{I}$ is an ideal radionuclide for the use of cancer diagnosis and therapy in nuclear medicine. However, in order to reach the desired target cells, ${ }^{131}$ I needs to bind to compounds that have pharmacological activity against cancer cells. In this study, the compound is piperine.

Piperine is one of the secondary metabolites in alkaloid group that can be isolated from the Piper nigrum and Piper longum plants. Piperine has a pale yellow crystal with a melting point of 128 $129^{\circ} \mathrm{C}$. Data analysis results from InfraRed spectrometry (IR), Nuclear Magnetic Resonance (NMR) and Mass Spectrometry (MS) showed that piperine isolates from Piper Nigrum plants had the molecular formula $\mathrm{C}_{17} \mathrm{H}_{19} \mathrm{NO}_{3}$ with a molecular weight of $285 \mathrm{~g} / \mathrm{mol}^{8}{ }^{8}$ Piperin is soluble in various organic solvents, such as petroleum ether, chloroform, ethanol, and methanol, but is not soluble in water. ${ }^{9}$ In several studies, piperine was shown to have various pharmacological activities, including as an antioxidant, antiinflammatory, antidiarrheal, anti convulsant, antimutagenic, hypolipidemic, increased bile secretion, and inhibitor of tumor cells. ${ }^{10}$ The inhibition activity of tumor cell growth by piperine is also confirmed by the study that showed piperine suppressed the growth of 4T1 breast tumors by inducing cell apoptosis, and preventing tumor cell metastasis at in vivo study. ${ }^{11}$ In addition, piperine was also proven to inhibit the growth of HT-29 colon cancer cells and induce apoptosis. ${ }^{12}$

Labeling of piperine with ${ }^{131} \mathrm{I}$ is expected to produce an ideal radiopharmaceutical for the use of diagnosis in early detection of cancer cells, as well as for the use of selective therapy for cancer cells.

\section{Materials and Methods}

\subsection{Materials}

The equipments to carry out this study were analytical scale (Mettler Toledo), dose calibrator (Victoreen), microtube, vortex (Barnstead Thermolyne), micropipette (Eppendorf), oven (Memert), a set of ascending paper chromatography and thin layer chromatography, tweezers, single channel analyzer (Ortec) and glassware commonly used in laboratories.

The materials used were piperine (isolated by STFI-pharmacochemical laboratory), Na- ${ }^{131} \mathrm{I}$ (Polatom), sodium metabisulfite (E.Merck), chloramine-T (SIGMA), phosphate buffer $\mathrm{pH}$ 7.4, absolute ethanol (E.Merck), aquadest (IPHA), methanol (E.Merck), dry methanol (E.Merck), ethyl acetate (E.Merck), toluene (E.Merck), Whatman No.1 paper and TLC-SG plate GF254 (E. Merck), and universal pH (E.Merck).

\subsection{Methods}

\subsubsection{Preparation of Solution}

a. Piperine Solution

Piperine $3 \mathrm{mg}$ was dissolved in $300 \mu \mathrm{L}$ of absolute ethanol.

b. Chloramine-T Solution

Chloramine-T $5 \mathrm{mg}$ was dissolved in 500 $\mu \mathrm{L}$ of phosphate buffer $\mathrm{pH} 7.4$

c. Na-metabisulfite Solution

Na-metabisulfite $5 \mathrm{mg}$ was dissolved in 
$500 \mu \mathrm{L}$ of phosphate buffer $\mathrm{pH}$ 7.4.

\subsubsection{Labeling of Piperine with Iodine-131}

In the microtube, $\mathrm{Na}^{-}{ }^{131} \mathrm{I}$ was added to the piperine solution ( $\mathrm{pH}$ was checked), then chloramine- $\mathrm{T}$ was added as an oxidizer. The mixture was then incubated for a few minutes while stirring using a vortex. Next, sodium metabisulfitewasadded(chloramine-Tvolume ratio: Na-metabisulfite $=1: 2$ ) to stop the reaction. The labeling process was considered complete. Then the final $\mathrm{pH}$ of the preparation was measured using $\mathrm{pH}$ universal indicator, and the radioactivity of the preparation was measured using a dose calibrator. Furthermore, the purity examination was carried out by paper chromatography and thin layer chromatography. The chromatogram was then counted using a Single Channel Analyzer (SCA) and the percentage of purity was calculated.

\subsubsection{Optimization of Labeling}

a. Optimization of Chloramine-T

Chloramine- $T$ as an oxidizer was added with a number of variations, namely 50 , $100,250 \mu \mathrm{g}$.

b. Optimization of Incubation Time

c. The labeling was done in various incubation time, namely $1,5,10,20$, and 30 minutes.

\subsubsection{Qualitative Characterization of}

${ }^{131}$ I-Piperine

Qualitative characterization of

${ }^{131}$ I-piperine was carried out by thin layer chromatogafi method. The stationary phase used was the TLC-SG GF-254 plate with toluene:ethyl acetate $(2: 1)$ as mobile phase. TLC plates were cut to a size of $10 \times 1 \mathrm{~cm}$ and marked every $1 \mathrm{~cm}$ with the number -1 to 8 . ${ }^{131}$ I-Piperine solution was spotted at 0 point. After elution, the plate was dried in an oven for several minutes. Then, spot of ${ }^{131}$ I-Piperin were observed under a $254 \mathrm{~nm}$ UV lamp. The $\mathrm{Rf}^{131}$ I-Piperine value was measured and compared with standard Piperin.

\subsubsection{Determination of Chromatography}

\section{Eluents}

Determination of eluents was done by paper chromatography and thin layer chromatography with the same procedure as in characterization. In paper chromatography, the stationary phase used was Whatman No.1 paper, while the stationary phase thin layer chromatography used was the TLCSG GF-254 plate. Various eluents used were aquadest, methanol $85 \%$, dry methanol, and toluene: ethyl acetate $(2: 1)$. After eluted and dried, the chromatogram was counted using a Single Channel Analyzer (SCA) to calculate radiochemical purity. Eluent which was able to obtain the best separation between labeledpiperine and radiochemical impurities was selected for the next stage of this study (purity test).

\subsubsection{Radiochemical Purity Test of}

\section{${ }^{131}$ I-Piperine}

The purity test was carried out by paper chromatography method with the stationary phase of Whatman No.1 paper and the mobile phase was selected from the previous stages of this study. ${ }^{131}$ I-piperine preparation were spotted on chromatographic paper and eluted. The chromatogram was counted using a Single Channel Analyzer (SCA) and the percentage of radiochemical purity was calculated. If the purity of the preparation did not meet the purity requirements for radiopharmaceutical preparations, it would be proceed with the purification stage.

\subsubsection{Purification}

${ }^{131}$ I-piperin were purified by ion exchange chromatography method. This method allows the separation between labeledpiperine and radiochemical impurities. The stationary phase used is Dowex 1X8 with several mesh variations, namely 50-100, 100200 , and 200-400, while the mobile phase is ethanol $70 \%$. The fractions were collected with each volume from 500 to $1000 \mu \mathrm{L}$, then radioactivity was measured by dose calibrator, and the yield and radiochemical purity were calculated.

\section{Results}

\subsection{Radioisotope Purity Test}

The $\mathrm{Na}^{131} \mathrm{I}$ preparation used met the requirements of radiochemical preparation for showing clear solution, $\mathrm{pH} 8-9$, and $98.662 \%$ \pm 0.149 of radiochemical purity according to the requirements set by the Ministry of Health in Indonesian Pharmacopoeia (FI) 
3.2. Labeling of Piperine with Iodine-131

Labeling of piperine with radioisotope

${ }^{131}$ I was carried out using Chloramine-T method through iodination process and electrophilic substitution. The structural prediction of the bond that occurs between ${ }^{131}$ I and piperine was done computationally as showed in Fig. 1.



Fig. ${ }^{131}$ I-piperine Structure Prediction
3.3. Qualitative Characterization of 131I-Piperine

The characterization was carried out for piperine standard and ${ }^{131} \mathrm{I}$-piperine by Thin Layer Chromatography (TLC) method with the stationary phase Silica gel GF 254 and toluene:ethyl acetate $(2: 1)$ as mobile phase. Observations were made under $254 \mathrm{~nm}$ and
$366 \mathrm{~nm}$ UV lamps. The piperine spot was black at $254 \mathrm{~nm}$ and blue at $366 \mathrm{~nm}$. There was no difference in the $\mathrm{Rf}$ value between the standard piperine and ${ }^{131} \mathrm{I}$-piperine: 0.56 , as showed in Fig.2.

\subsection{Determination of Chromatography} Eluents

The eluents tested were (A) toluene:ethyl acetate (2:1), (B) methanol $85 \%$, (C) dry methanol, and (D) aquadest. Aquadest was the eluent which could separate ${ }^{131}$ I-piperine from radiochemical impurities (Fig.3).

\subsection{Optimization of Labeling}

\subsubsection{Optimization of Chloramine-T}

The optimization of oxidizing agent was carried out with several variations of the amount of chloramine-T used, namely 50, 100 , and $250 \mu \mathrm{g}$ with an incubation time of 10 minutes. The radiochemical purity obtained were $28.868 \pm 0.035 ; 36.649 \pm 0.515$; and $36.527 \pm 4.662$ respectively.
For the addition of $50 \mu \mathrm{g}$ of chloramine-T produced a more stable preparation (without precipitation), and an increase in the amount of chloramine-T did not produce a significant increase in purity, then the chloramine-T amount of $50 \mu \mathrm{g}$ was chosen for the next labeling formula. The optimization of labeling was continued with the variation of incubation time.

\subsubsection{Optimization of Incubation Time}

The labeling result with the highest radiochemical purity value $43.99 \% \pm 1.23$ was achieved with an incubation time of 30 minutes but not fulfilled the requirement of radiochemical purity (Fig 4). It was necessary to purify the preparation by ion exchange chromatography method.

\subsection{Purification}

Purification method was carried out using anion exchange resin, namely Dowex $1 \mathrm{X} 8$ with $50-100$ mesh size variations; 100 -



Fig. 2 Piperine standard and ${ }^{131}$ I-piperine Chromatogram 


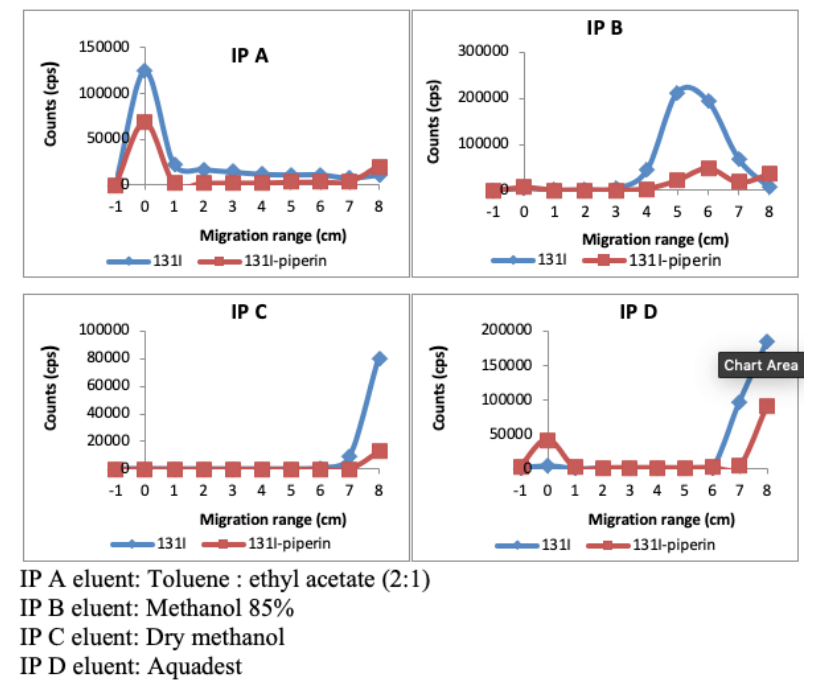

Fig. 3 Counting Profile of ${ }^{131}$ I-Piperin

200; and 200-400.

The best purification results were obtained by purification using Dowex 1X8 mesh 100-200 resin with a column diameter of $0.6 \mathrm{~cm}$; column height of $4-5 \mathrm{~cm}$; and fraction volume of $500 \mu \mathrm{L}$. The radiochemical purity of the ${ }^{131}$ I-piperine preparations obtained had fulfilled the requirements of radiopharmaceutical purity, $93.26 \% \pm 0.94$.

\section{Discussion}

\subsection{Radioisotope Purity Test}

The radiochemical purity of radioisotope Iodine-131 in the form of $\mathrm{Na}^{131}$ I solution was determined according to the requirements set by the Ministry of Health in Indonesian Pharmacopoeia, including: ${ }^{13}$

\subsubsection{Clarity}

Clarity test were done with visual method. $\mathrm{Na}^{131}$ I preparations showed the results of a clear solution in the absence of impurity particles and fulfilled the requirement.

\subsection{2.pH}

$\mathrm{PH}$ test for $\mathrm{Na}^{131} \mathrm{I}$ preparations were carried out using a universal $\mathrm{pH}$ indicator. The $\mathrm{pH}$ range specified in the $\mathrm{FI}$ for the $\mathrm{Na}^{131} \mathrm{I}$ solution is between 7.5 and 9 . The $\mathrm{Na}^{131} \mathrm{I}$ solution showed a $\mathrm{pH}$ range of 8-9.

\subsubsection{Radiochemical Purity}

Radiochemical purity test of $\mathrm{Na}^{131} \mathrm{I}$ preparation was carried out by paper chromatography method using Whatman No.1 paper as a stationary phase and methanol: water $(85: 15)$ as the mobile phase. This eluent was chosen because it could separate ${ }^{131} \mathrm{I}$ from radiochemical impurities such as iodate ions $\left(\mathrm{IO}_{3}^{-}\right) \cdot \mathrm{Na}^{131} \mathrm{I}$ purity was characterized based on the Rf value and the results of the paper counts using SCA. The Rf value of ${ }^{131} \mathrm{I}$ was 0.7 , while $\mathrm{IO}_{3}{ }^{-} \mathrm{Rf}$ value was $0.4{ }^{14}$

4.2. Labeling of Piperine with Iodine-131

Chloramine-T method was chosen for high specific activity compounds could be obtained by this method and the labeling effieciency can be very high $(\sim 90 \%){ }^{15}$

The reaction that occurs in labeling of piperine with ${ }^{131} \mathrm{I}$ is an electrophilic substitution because piperine does not have an iodine atom in its structure. Through electrophilic substitution, the most stable bond between ${ }^{131} \mathrm{I}$ and piperine occurs in $\mathrm{C}$ atoms located between two ether groups. In this case ${ }^{131}$ I replaces the position of one of the $\mathrm{H}$ atoms (Fig.1)

4.3. Qualitative Characterization of
${ }^{131}$ I-Piperine
By comparing the chromatographic profile between standard piperine and ${ }^{131}$ I-piperine, it is known that labeling piperine with ${ }^{131}$ I did not cause changes in the properties of piperine for there was no difference in the $\mathrm{Rf}$ value between the standard piperine and ${ }^{131}$ I-piperine (Fig.2).
4.4. Determination of Chromatography Eluents
Determination of chromatographic 
eluents is important, especially for purity test of the labeled-compound. The chosen chromatographic eluent here was the one which could separate ${ }^{131} \mathrm{I}$-piperine from radiochemical impurities. These radiochemical impurity were derived from an imperfect labeling process. They could be in the form of $\mathrm{I}^{-}, \mathrm{IO}_{3}^{-}$, and $\mathrm{IO}_{4}^{-}$.

From Fig. 3 (IP D), we could see that ${ }^{131}$ I-piperine remained at the point of spotted, while iodine impurities moved with eluent (aquadest). Therefore, aquadest was chosen as the eluent used for the purity test of ${ }^{131}$ I-piperine at the next stage.

\subsection{Optimization of Labeling}

\subsubsection{Optimization of Chloramine- $T$}

Determination of the amount of oxidizing agent is very important in reducing the radiochemical impurities formed. In addition, the right amount of oxidizing agents can also minimize the damage to the compounds that will get labeled and/or the labeled-compounds formed.

The addition of chloramine-T amount produced a better purity of the ${ }^{131} \mathrm{I}$-piperine preparation. However, precipitate was formed with the addition of 100 and $250 \mu \mathrm{g}$ chloramine-T. The precipitate was centrifuged and separated from the supernatant, and then it was dissolved with the solvents used to dissolve piperine or chloramine-T, namely ethanol and phosphate buffer. As a result, the precipitate dissolved in phosphate buffer. It was suspected that the sediment was not piperine. However, further research is needed to identify the precipitate formed.

\subsubsection{Optimization of Incubation Time}

Incubation time that was too short could cause a labeling reaction that did not work perfectly, on the other hand, the long incubation time could cause damage to the labeled-compound because of long interaction with the oxidizing agent.

The labeling result with the highest radiochemical purity value $43.99 \% \pm 1.23$ was achieved with an incubation time of 30 minutes as showed in Fig 4.

\subsection{Purification}

Radiochemical impurities were in the form of anions, such as $\mathrm{I}^{-}, \mathrm{IO}_{3}^{-}$, and $\mathrm{IO}_{4}^{-}$, therefore purification method was carried out using anion exchange resin.

Dowex $1 \mathrm{X} 8$ is a strong base type anion exchange resin with chloride anion in it. Ion exchange occured between $\mathrm{I}^{-}, \mathrm{IO}_{3}^{-}$, and $\mathrm{IO}_{4}^{-}$ions, with $\mathrm{Cl}^{-}$ions. The radiochemical impurities binded stronger with resin than Clions so that they would be retained in the resin, while ${ }^{131} \mathrm{I}$-piperine would come out with eluent (70\% ethanol).

Purification started by using a column with a diameter of $1.5 \mathrm{~cm}$ and a height of $4-5 \mathrm{~cm}$ with Dowex 1X8 mesh 50-100. The fractions were collected to 10 fractions with each volume of $1 \mathrm{~mL} .{ }^{131} \mathrm{I}$-piperine was considered to be in the $2^{\text {nd }}$ and $3^{\text {rd }}$ fractions, because in other fractions, the activity detected was very small and almost undetectable as showed in Table 1. Radiochemical purities obtained were $63.04 \%$ and $49.33 \%$ with yields of $2.36 \%$ and $1.18 \%$ respectively.

With the same treatment, purification was also carried out with Dowex 1X8 mesh 100-200. The fraction were collected to 5 fractions with volume of $1 \mathrm{~mL}$. With this treatment, ${ }^{131}$ I-piperine was in the 4 th fraction with a slight increase in Radiochemical Purityto $69.91 \%$ and yields to $3.03 \%$.

Purification with 200-400 Dowex 1X8 mesh with the same treatment did not provide good results. From the whole purification using a column with a diameter of $1.5 \mathrm{~cm}$ and a height of $4-5 \mathrm{~cm}$, the results of the radiochemical purity of the preparation did not meet the requirement of the purity for radiopharmaceutical preparation. Besides, the yields produced was also very minimal. This might be caused by the dimension of the column which was too large so that the ${ }^{131}$ I-piperine elution process did not work well for ${ }^{131}$ I-piperine was trapped in the resin. Therefore, purification was continued with smaller column dimensions, with a diameter of $0.6 \mathrm{~cm}$ and a height of $4-5 \mathrm{~cm}$ using a 100-200 Dowex 1X8 mesh resin which had previously produced the best purity and yields.

By the results shown from the Table 2, it is known that there had been an increase in 


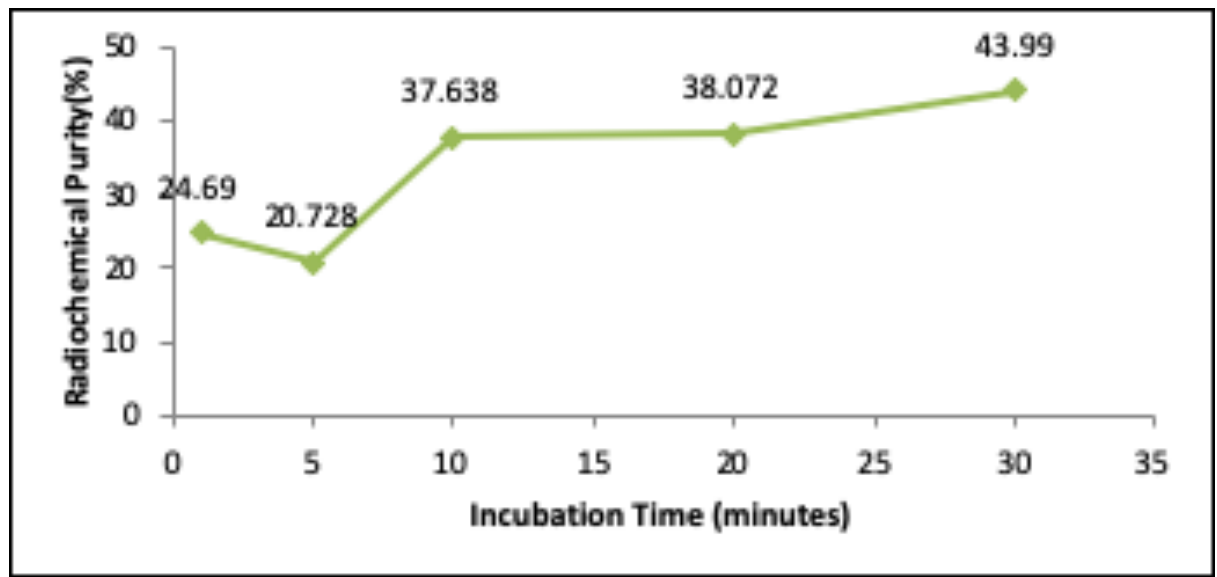

Fig. 4 Radiochemical Purity on Optimization of Incubation Time

Table $1{ }^{131}$ I-piperin Fractination by Dowex 1X8 mesh 50-100

\begin{tabular}{ccc}
\hline Resin & Fractions & Radioactivity (mCi) \\
\hline & 1 & 0 \\
& 2 & 0.010 \\
& 3 & 0.005 \\
Dowex 1X8 & 4 & 0.002 \\
mesh 50-100 & 5 & 0.002 \\
& 6 & 0.001 \\
& 7 & 0.001 \\
& 8 & 0.001 \\
& 9 & 0.001 \\
& 10 & 0.001 \\
\hline
\end{tabular}

Table $2{ }^{131}$ I-piperin Purification by Dowex 1X8 mesh 100-200 with Column Diameter $0.6 \mathrm{~cm}$ a. Fractions volume of $1 \mathrm{~mL}$

\begin{tabular}{cccccc}
\hline \multirow{2}{*}{ Fractions } & \multicolumn{2}{c}{ Radioactivity $(\mathbf{m C i})$} & \multicolumn{2}{c}{ Radiochemical Purity(\%) } & \multirow{2}{*}{ Yields $(\%)$} \\
\cline { 2 - 5 } & Before & After & Before & After & 11.30 \\
\hline 1 & & 0.019 & & 86.206 & 4.17 \\
2 & & 0.007 & & 88.565 & 2.98 \\
3 & 0.168 & 0.005 & 43.12 & 95.556 & 1.78 \\
4 & & 0.003 & & 87.853 & 1.78 \\
5 & & 0.003 & & - & \\
\hline
\end{tabular}

b. Fractions volume of $500 \mu \mathrm{L}$ (1)

\begin{tabular}{cccccc}
\hline \multirow{2}{*}{ Fractions } & \multicolumn{2}{c}{ Radioactivity (mCi) } & \multicolumn{2}{c}{ Radiochemical Purity(\%) } & \multirow{2}{*}{ Yields (\%) } \\
\cline { 2 - 4 } & Before & After & Before & After & \\
\hline 1 & & 0.012 & & 87.487 & 4.10 \\
2 & & 0.017 & & 90.261 & 5.80 \\
3 & 0.293 & 0.004 & 22.10 & 85.608 & 1.37 \\
4 & & 0.004 & & 82.642 & 1.37 \\
5 & & 0.004 & & 93.046 & 1.37 \\
\hline
\end{tabular}

c. Fractions volume of $500 \mu \mathrm{L}(2)$

\begin{tabular}{cccccc}
\hline \multirow{2}{*}{ Fractions } & \multicolumn{2}{c}{ Radioactivity (mCi) } & \multicolumn{2}{c}{ Radiochemical Purity(\%) } & \multirow{2}{*}{ Yieds (\%) } \\
\cline { 2 - 5 } & Before & After & Before & After & \\
\hline 1 & & 0.000 & & 89.842 & 0 \\
2 & & 0.014 & & 93.255 & 7.29 \\
3 & 0.192 & 0.000 & 26.63 & - & 0 \\
4 & & 0.000 & & - & 0 \\
5 & & 0.000 & & - & 0 \\
\hline
\end{tabular}


radiochemical purity, which reached $86.21 \%$ and $88.57 \%$ and the yield $11.30 \%$ and $4.17 \%$.

However, purification continued with a decrease in fraction volume from $1 \mathrm{~mL}$ to 500 $\mu \mathrm{L}$ in order to obtain the preparations with better radiochemical purities.

The best purification results were obtained by purification using Dowex 1X8 mesh 100-200 resin with a column diameter of $0.6 \mathrm{~cm}$; column height of $4-5 \mathrm{~cm}$; and fraction volume of $500 \mu \mathrm{L}$. The radiochemical purity of the ${ }^{131}$ I-piperine preparations obtained had met the requirements of radiopharmaceutical purity, $93.26 \% \pm 0.94$.

\section{Conclusion}

Piperine was able to be labeled with radioisotope ${ }^{131} \mathrm{I}$ using Chloramine-T method. The labeling was done with piperine formula $3 \mathrm{mg} / 300 \mu \mathrm{L}$, chloramine-T $50 \mu \mathrm{g}$, incubation time 30 minutes, and sodium metabisulfite $100 \mu \mathrm{g}$ with radiochemical purity of $43.99 \%$ \pm 1.23 . Therefore, to improve the purity of the preparations, purification was carried out by anion exchange chromatography method using Dowex 1X8 mesh 100-200 resin with $0.6 \mathrm{~cm}$ column diameter and $4-5 \mathrm{~cm}$ column height, and ethanol $70 \%$ as eluent. The labeling results with this method had met the requirements of radiopharmaceutical purity, which was $93.26 \% \pm 0.94$ with a yield of $5 \%$ to $7.29 \%$.

\section{References}

1. Kementerian Kesehatan. Situasi Penyakit Kanker. Buletin Jendela Data dan Informasi Kesehatan. 2015;1:6-7

2. Sabrida H. Peranan Deteksi Dini Kanker untuk Menurunkan Penyakit Kanker Stadium Lanjut. Buletin Jendela Data dan Informasi Kesehatan. 2015;1:16

3. Morris CR, Ramirez CN, Cook SN, Parikh-Patel A, Kizer KW, Bates JH, et al. Cancer Stage at Diagnosis. California Cancer Registry. 2013;3

4. Wijaya CA, Muchtaridi M. Pengobatan Kanker Melalui Metode Gen Terapi. Farmaka. 2017;15(1):54

5. lem-Özdemir D, Ekinci M, Gündoğdu E, Aşıkoğlu M. Estimating Binding
Capability of Radiopharmaceuticals by Cell Culture Studies. Int J Med Nano Res. 2016;3(1):014

6. Sen DJ. Nuclear Medicine As Radionuclide in Radiopharmaceutical in Scintigraphy. World J Pharm Res. 2018;7(13):755-90

7. Silberstein EB, Alavi A, Balon HR, Clarke SEM, Divgi C, Gelfand MJ, et al. The SNM Practice Guideline for Therapy of Thyroid Disease with ${ }^{131} \mathrm{I}$. J Nuclear Medicine. 2012;53(10):2

8. Saha KC, Seal HP, Noor MA. Isolation and Characterization of Piperine from the Fruits of Black Pepper (Piper nigrum). $J$ Bangladesh Agril Univ. 2013;11(1):11-6

9. Kolhe SR, Borole P, Patel U. Extraction and Evaluation of Piperine from Piper nigrum Linn. Int $J$ Applied Biology and Pharm Tech. 2011;2(2):144

10. Lu J, Bao J, Chen X, Huang M, Wang Y. Alkaloids Isolated from Natural Herbs as the Anticancer Agents. EvidenceBased Complementary and Alternative Medicine. 2012;2012:3

11. Lai L, Fu Q, Liu Y, Jiang K, Guo Q, Chen Q, et al. Piperine Suppresses Tumor Growth and Metastasis In Vitro and In Vivo in a 4T1 Murine Breast Cancer Model. Acta Pharmacologica Sinica. 2012;33:523-30

12. Yaffe PB, Coomb MRP, Doucette CD, Walsh M, Hoskin DW. Piperine, an Alkaloid From Black Pepper, Inhibits Growth of Human Colon Cancer Cells Via G1 Arrest and Apoptosis Triggered by Endoplasmic Reticulum Stress. Molecular Carcinogenesis. 2014;10-2

13. Kementrian Kesehatan. Farmakope Indonesia. Edisi V. Jakarta: Kementrian Kesehatan; 2014

14. Kahn M, Kleinberg J. Radiochemistry of Iodine. US: ERDA; 1977

15. Saha GB. Fundamentals of Nuclear Pharmacy $5^{\text {th }}$ Ed. New York: Springer Science; 2004 